\title{
A COMPARISON OF SLIT-LAMP SUPPORTED VERSUS HAND-HELD BIOMETRY
}

\author{
I. M. WHELEHAN ${ }^{1}$, P. HEYWORTH ${ }^{1}$, H. TABANDEH ${ }^{2}$, S. McGUIGAN ${ }^{2}$ and A. j. E. FOSS \\ London
}

\begin{abstract}
SUMMARY
Biometry allows determination of the final refractive outcome following cataract extraction with intraocular lens implantation. We compared the accuracy of axial length measurement performed with the slit-lamp supported biometry probe versus a hand-held technique. The two methods of biometry were performed on 32 patients undergoing endocapsular cataract extraction with lens implantation. One of the methods was selected at random in order to predict implant power for a desired refractive outcome using the SRK-T formula. There was no difference in 'within-subject' variance of axial length measurement between the two methods $(t=1.74, p=0.091)$, and there was no difference in refractive outcome when the power calculations for the two techniques were compared $(t=0.12$, $p=0.906)$. The hand-held technique provides a useful alternative method of biometry in 'difficult' patients.
\end{abstract}

Biometry is usually performed with the ultrasound probe supported on a tonometer carriage, with the patient's head supported on a chin rest and the forehead held against a head band. Elde ${ }^{-1 /}$ infirm patients, those with spondylosis and children find this arrangement awkward, making accurate easurement difficult. An alternative method is to old the ultrasound probe manually without requiring the patient to adopt a pre-determined position. The purpose of this prospective itudy was 1. compare the accuracy of slit-lamp versus hand-held biumetry.

\section{MATERIALS AND METHODS}

Thirty-two patients were studied. All underwent biometry using the slit-lamp (SL) and the handheld $(\mathrm{HH})$ techniques with the Allergan Humphrey applanation biometer (model 820). Examinations were performed by four of the authors, although

From: ${ }^{1}$ Moorfields Eye Hospital, London; ${ }^{2}$ St George's Hospital, London, UK.

Correspondence to: Miss I. M. Whelehan, BSc, MBBS, FRCOphth, Ophthalmology Department, Royal Hallamshire Hospital, Glossop Road, Sheffield S10 2JF, UK. both methods of biometry were performed by the same examiner in each patient. The order in which the two methods were used was not randomised; the authors did not think that bias would be introduced for either method, since the acceptance of a reading was based upon the quality of the scan and not on the measurement. Seven measurements were taken for each method, and a trimmed mean was calculated by discarding the highest and the lowest measurements. Axial length, keratometry and desired refraction were entered into the SRK-T ${ }^{1}$ formula to calculate the lens power required to achieve desired refraction for each technique.

One of the biometry methods was randomly selected, the implant pow $r$ to achieve a desired refraction was then chosen and the appropriate implant inserted during endocapsular surgery. All patients received $7 \mathrm{~mm}$ IOLAB PMMA implants. Patiants were refracted 3 months following surgery. The difference between the predicted and achieved refractive outcome for the selected method was calculated. The accuracy of the other (non-selected) method was assessed by comparing the refractive outcome preainted by that technique for the implant power inserted with the observed final refraction.

\section{RESULTS}

\section{Axial Length Measurement}

Thirty-two patients had axial length measurements by the SL and $\mathrm{HH}$ techniques. Reproducibility was assessed by calculating the 'within-subject' variance ${ }^{2}$ for each patient (Table I, columns 3 and 5) and comparing the two methods with a paired $t$-test. This showed a trend towards increased variance for the $\mathrm{HH}$ method but did not reach significance $(t=-1.74$, $p=0.091$ ).

The mean axial lengths for both methods were compared for each patient. Agreement between the two methods was assessed using a standard plot of the difference between the two methods (HH-SL) versus their average ${ }^{2}$ (Fig. 1); this graph shows no 
Table I. Comparison and statistical analysis of the slit-lamp and hand-held biometry methods

\begin{tabular}{|c|c|c|c|c|c|c|}
\hline Case no. & $\begin{array}{l}\text { Trimmed mean } \\
\text { axial length, slit- } \\
\text { lamp (mm) }\end{array}$ & $\begin{array}{l}\text { Variance, slit- } \\
\text { lamp }(\mathrm{mm})\end{array}$ & $\begin{array}{l}\text { Trimmed mean } \\
\text { axial length, hand- } \\
\text { held }(\mathrm{mm})\end{array}$ & $\begin{array}{l}\text { Variance, hand- } \\
\text { held (mm) }\end{array}$ & $\begin{array}{l}\delta \text { refraction, slit- } \\
\text { lamp (DS) }\end{array}$ & $\begin{array}{c}\delta \text { refraction, hand- } \\
\text { held (DS) }\end{array}$ \\
\hline 1 & 23.042 & 0.05812 & 23.004 & 0.09548 & 1.41 & 1.36 \\
\hline 2 & 23.506 & 0.15868 & 22.348 & 0.01567 & 2.55 & 0.33 \\
\hline 3 & 24.62 & 0.01535 & 23.876 & 0.03733 & N/A & N/A \\
\hline 4 & 23.49 & 0.0031 & 23.658 & 0.20162 & -1.112 & -0.73 \\
\hline 5 & 24.332 & 0.07627 & 23.474 & 0.00838 & 0.33 & -1.45 \\
\hline 6 & 23.678 & 0.03357 & 23.642 & 0.03667 & -1.2 & -1.11 \\
\hline 7 & 22.966 & 0.51773 & 21.614 & 0.02183 & -0.75 & -1.08 \\
\hline 8 & 21.966 & 0.42143 & 22.026 & 0.47518 & 0.14 & 1.01 \\
\hline 9 & 25.9 & 0.29825 & 22.088 & 0.25557 & -3.6 & 0.885 \\
\hline 10 & 23.73 & 0.03365 & 24.07 & 0.11425 & N/A & N/A \\
\hline 11 & 24.6 & 0.03435 & 24.356 & 0.40218 & -0.1 & -0.65 \\
\hline 12 & 22.744 & 0.00273 & 22.052 & 0.09175 & N/A & N/A \\
\hline 13 & 22.018 & 0.00132 & 23.09 & 101108 & 0.25 & 1.2 \\
\hline 14 & 21.114 & 0.02303 & 21.552 & 0.01042 & -0.545 & 0.495 \\
\hline 15 & 23.792 & 0.02772 & 23.424 & 0.03263 & 0.83 & -0.34 \\
\hline 16 & 23.348 & 0.11222 & 23.614 & 0.19133 & 0.49 & 1.23 \\
\hline 17 & 23.098 & 0.00072 & 23.126 & 0.01003 & 0.405 & 0.475 \\
\hline 18 & 21.02 & 0.00205 & 21.81 & 0.4446 & 0.83 & 2.82 \\
\hline 19 & 22.122 & 0.01152 & 22.47 & 0.74455 & 1.14 & 1.96 \\
\hline 20 & 24.316 & 0.42788 & 23.8 & 0.16435 & 1.595 & 0.505 \\
\hline 21 & 23.694 & 0.00668 & 24.006 & 0.01403 & -1.32 & -0.69 \\
\hline 22 & 22.454 & 0.25513 & 22.204 & 0.01808 & 0.51 & 0.98 \\
\hline 23 & 22.636 & 0.01268 & 24.288 & 0.03487 & 1.02 & 4.71 \\
\hline 24 & 23.98 & 0.12665 & 23.312 & 0.00297 & -0.13 & -1.53 \\
\hline 25 & 22.928 & 0.00757 & 22.73 & 0.0214 & N/A & N/A \\
\hline 26 & 24.744 & 0.07398 & 25.042 & 0.45192 & -0.88 & -0.33 \\
\hline 27 & 22.106 & 0.00813 & 22.362 & 0.54137 & 0.09 & -0.72 \\
\hline 28 & 22.86 & 0.42685 & 22.338 & 0.00697 & 2.14 & 0.78 \\
\hline 29 & 22.47 & 0.00635 & 22.728 & 0.17502 & 0.91 & 1.51 \\
\hline 30 & 22.658 & 0.35707 & 22.704 & 0.77563 & 2.19 & 2.29 \\
\hline 31 & 22.106 & 0.00813 & 22.362 & 0.54137 & N/A & N/A \\
\hline 32 & 22.454 & 0.25513 & 22.204 & 0.01808 & -0.35 & -0.12 \\
\hline
\end{tabular}

systematic variation between the techniques and no discernible pattern. The $95 \%$ confidence interval of agreement between the two methods is between $-1.1 \mathrm{~mm}$ and $+1.2 \mathrm{~mm}$.

\section{Refractive Outcome}

Twenty-seven patients had completed refraction at 3 months. The predicted refractive outcome for the chosen implant power for both methods was compared with the spherical equivalent of the actual

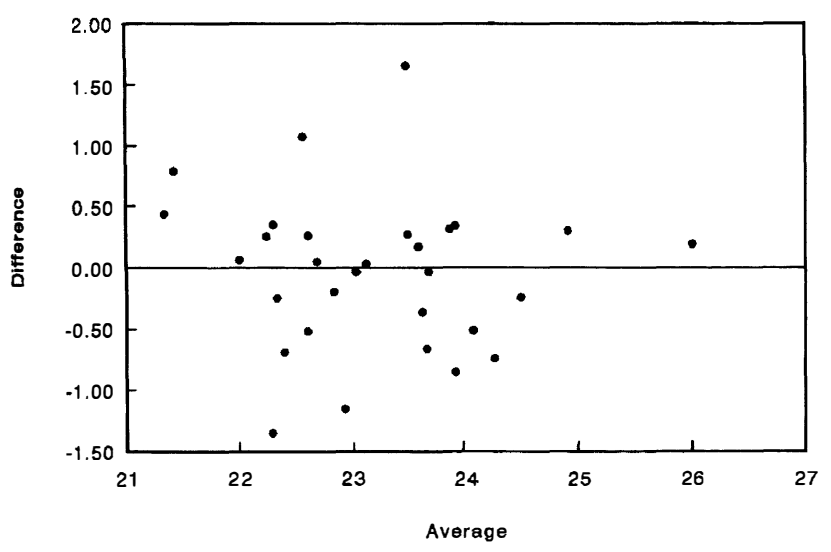

Fig. 1. Difference in axial length measurement between hand-held and slit-lamp methods $(H H-S L)$ plotted against average $(H H+S L / 2)$, showing no systematic bias between the two methods. refractive outcome. Mean difference from predicted refraction (in dioptres) for the slit-lamp method was 0.61 (SD 1.05) and for the hand-held method was 0.58 (SD 1.43) (Table II). A paired $t$-test was applied to the means $(t=0.12, p=0.906)$ and showed no statistical difference between the two methods. There was a trend towards increased variation in the hand-held method but this was not significant $(F=0.54, p=0.12)$.

\section{DISCUSSION}

The power of an intraocular lens (IOL) needed to achieve the desired refraction after cataract extraction can be calculated from pre-operative measurements of the corneal power and the axial length. ${ }^{3.4}$ Large refractive 'surprises' can result in asthenopic symptoms, commonly as a result of binocular diplopia and altered depth perception, and in some cases a second operation may be required to exchange the IOL for one of a different power. Accurate prediction of IOL power is therefore desirable. A difference of greater than 2 dioptres from predicted was found in 4 of $27(14.8 \%)$ of the slit-lamp group and 3 of 27 (11.1\%) of the hand-held group. This is a relatively small series and we cannot dispute that the degree of error is higher than in other, larger series. The biometer was calibrated and found to be functioning normally. None of the 6 
Table II. Difference between expected and measured refractive outcomes for the slit-lamp and hand-held biometry techniques

\begin{tabular}{lccccc}
\hline & Sample size & Min. (DS) & Max. (DS) & Mean (DS) & SD \\
\hline$\delta$ refraction slit-lamp & 27 & -3.6 & +2.55 & 0.61 & 1.05 \\
$\delta$ refraction hand-held & 27 & -1.53 & +4.71 & 0.58 & 1.43 \\
\hline
\end{tabular}

patients in this series with a final refraction of greater than 2 dioptres from predicted suffered asthenopic symptoms.

The accuracy of IOL calculation is influenced by several factors including the IOL type and its position, corneal curvature readings, and axial length recordings. ${ }^{5,6}$ Studies have shown axial length to be the single most important parameter in the calculation, ${ }^{7}$ being responsible for up to $54 \%$ of any unexpected refraction, compared with $11 \%$ associated with keratometric error. ${ }^{8}$ Accurate axial length determination in the elderly infirm patient or those with spondylosis presents a challenging problem; difficulty with positioning of the patient on the chin rest can lead to incorrect readings due to poor alignment of the probe and possible excess shortening of the globe as the patient finds it difficult to remain still. A comparison of contact versus a noncontact immersion technique demonstrated superior results of the latter in the older and unstable fixated patient's eye due to less shortening of the globe, ${ }^{9}$ but this method is time consuming, and requires more instrumentation and further training for the technician.

A compromise between accuracy and practicality has to be sought when measuring axial length in these 'difficult' patients. The hand-held contact technique described in this study provides an alternative method of axial length determination. It may be postulated that the hand-held method of contact biometry is less accurate than the slit-lamp mounted probe, due to difficulties with adequate fixation, alignment of the probe with the visual axis and excessive corneal indentation. Significant corneal indentation and resultant apparent shortening of the globe occurs in all manual applanation techniques. Studies using a Biopen (similar to the hand-held method) have shown the effect on refractive outcome to be minimal. ${ }^{10}$ This series shows that using a biometry probe from a slit-lamp supported system by hand still gives an unbiased estimate of the axial length. However, a more accurate estimate can be made by repeated measurements (standard error of the mean $=\mathrm{SD} / \sqrt{n}$, where $n$ is the number of measurements). The hand-held method has a trend towards increased standard deviation; if this is thought to be unacceptably high it can readily be compensated for by increasing the number of repeat measurements. The tendency for decreasing accuracy with increasing difference in axial length from the population median was not identified in this group as it did not contain many patients with excessively long or short eyes. This study shows that the hand-held method of biometry is an acceptable alternative in patients unable to manage the slit-lamp method for whatever reason.

Key words: Biometry, Axial length, Intraocular lens implant, Refraction.

\section{REFERENCES}

1. Retzlaff J, Sanders D, Kraff M. A manual of implant power calculation. Oregon: Medford, 1982.

2. Altman DG. Practical statistics for medical research. 1st ed. London: Chapman and Hall, 1991.

3. Olsen $T$. Theoretical approach to intraocular lens calculation using Gaussian optics. J Cataract Refract Surg 1987;13:141-5.

4. Fyodorov SN, Galin MA, Linksa A. Calculation of the optical power of intraocular lenses. Invest Ophthalmol 1975;14:625-8.

5. McEwan JR, Massengill RK, Samuel D, et al. Effect of keratometer and axial length measurement errors on primary implant power calculations. J Cataract Refract Surg 1990;16:61-70.

6. Shammas HJF. Axial length measurement and its relation to intraocular lens power calculations. Am Intra-Ocular Implant Soc J 1982;8:346-9.

7. Olsen T. Calculating axial length in the aphakic and pseudophakic eye. J Cataract Refract Surg 1988;15: 413-6.

8. Holladay JT, Prager TC, Ruiz RS, et al. Improving the predictability of intraocular lens power calculations. Arch Ophthalmol 1986;104:539-41.

9. Schelenz J, Kammann J. Comparison of contact and immersion techniques for axial length measurement and implant power calculation. J Cataract Refract Surg 1989;15:425-8.

10. Shammas JH, Swearingen M. Clinical evaluation of the Bio-pen for axial length measurement. J Cataract Refract Surg 1990;16:120-2. 